\title{
Systemic Lupus Erythematosus with Multiple Faces in a Girl of 11 Years
} Abul Khair Ahmedullah ${ }^{1 *}$, Abhijit Datta ${ }^{2}$,Zinat Nasrin ${ }^{3}$, Md. Nazmul Hasan ${ }^{4}$, Md. Masudul Hassan ${ }^{5}$, Md. Nazrul Islam ${ }^{6}$

\author{
${ }^{1}$ Assistant Professor, Department of Rheumatology, BSMMU, Dhaka, Bangladesh \\ ${ }^{2}$ Phase B resident, Department of Rheumatology, BSMMU, Dhaka, Bangladesh \\ ${ }^{3}$ Assistant Professor, Department of Radiology and Imaging, National Institute of Ophthalmology, Dhaka, Bangladesh \\ ${ }^{4}$ Assistant Professor, Department of Internal Medicine, BSMMU, Dhaka, Bangladesh \\ ${ }^{5}$ Medical Officer, Department of Rheumatology, BSMMU, Dhaka, Bangladesh \\ ${ }^{6}$ Professor \& Chairman, Department of Rheumatology, BSMMU, Dhaka, Bangladesh
}

*Corresponding author: Abul Khair Ahmedullah

Abstract

Systemic lupus erythematosus in children (childhood onset SLE/cSLE) have a great variability in disease presentation. Any organ system can be involved in cSLE leading to protean clinical manifestations. In this case report, we present a 11-year-old Bangladeshi girl who presented with inflammatory pain in multiple joints, high-grade intermittent fever, headache, high blood pressure, and generalized tonic-clonic seizures. Detailed clinical examination with laboratory and imaging studies clinched the diagnosis of SLE and the involved organs include skin, mucosa, joint, haemopoietic system, kidney, and brain. In presenting this case and reviewing the literature, we emphasize the importance of very high index of suspicion for diagnosis of cSLE for early diagnosis, treatment and meticulous monitoring.

Keywords: Childhood onset systemic lupus erythematosus (cSLE), seizure, adult SLE (aSLE), glomerulonephritis, central nervous system.

Copyright @ 2020: This is an open-access article distributed under the terms of the Creative Commons Attribution license which permits unrestricted use, distribution, and reproduction in any medium for non-commercial use (NonCommercial, or CC-BY-NC) provided the original author and source are credited.

\section{INTRODUCTION}

SLE in childrenmay present with multiple faces with variable course of the disease [1,2]. Multiple organsystems can be involved simultaneously or in a rapid sequence [1-3]. The incidence and prevalence ofcSLE ranges from $0.36-2.5 / 100,000 /$ year and 1.89 - $25.7 / 100,000$ respectively [4]. Presentation of cSLE among different ethnic groups has also variability $[5,6]$. Reports are available showing cSLE presenting with more acute illness and having more frequent renal, he matological and neurological involvement within short course of time compared to adult SLE [7]. Reporting this case aims to emphasize the importance of very high index of suspicion for early diagnosis of cSLE, treatment and monitoring.

\section{Case Summary}

A 11-year-old Bangladeshi school girl presented with inflammatory pain in the multiple joints symmetrically involving small and large joints of upper and lower limbs for seven weeks, swelling of the face for three weeks, and headache for seven days. The swelling did not involve the other parts of the body, improved partially with diuretics, and was associated with reduction in volume and dark colorization of urine.
The headache was pulsatile, occasionally hemicranial, associated with nausea and vomiting; was not associated with increase in early morning, coughing, bending and straining; without any visual impairment, photophobia, redness of eye and lacrimation. During the course of illness, she had high-grade, intermittent fever, without shaking chills, persisted for initial three weeks. Exclusion of infection and non-respose to empirical broad spectrum antibiotic led physicians to search for the presence of a multi-system connective tissue disorder. The fever subsided with initiation of glucocorticoid. She was admitted into hospital due to generalized tonic-clonic seizure nine times with tongue biting during the episodes of seizure three times. Infectious, metabolic and other causes of seizure were excluded. She had no significant past history and family history. She had not developed menarche still.

Examination revealed mild anaemia, high blood pressure $(170 / 90 \mathrm{mmHg}$ ) and puffy face. As she was significantly improved on medication, clinical examination revealed normal other findings. Routine urine examination showed protein-(3+), red blood cells20-30/high power field, WBC-plenty/high power field. Urinary total protein (UTP) was $1.7 \mathrm{~g} / 24$ hours. Full blood count showed features of pancytopenia. Antinuclear antibody (ANA) and anti-ds DNA were positive 
in high-titer and complements were reduced. Serum creatinine, electrolytes and hepatic enzymes were within normal limit. Renal biopsy was advised but patient's parents did not agree to let their daughter to undergo biopsy procedure.

\section{TREATMENT}

The patient was dramatically improved after starting steroids. Initially soon after diagnosis, she was put on hydroxychloroquine (HCQ), oral prednisolone $0.5 \mathrm{mg} / \mathrm{kg} / \mathrm{day}$, and naproxen $250 \mathrm{mg} 12$ hourly. But 10days after initiation of therapy she developed seizure attacks. She was hospitalized and received intravenous pulse methylprednisolone at 500mg daily for 3 days, followed oral prednisolone $1 \mathrm{mg} / \mathrm{kg} /$ day. She also received IV pulse cyclophosphamide $750 \mathrm{mg} / \mathrm{square}$ meter body surface area. Her blood pressure was controlled with captopril $50 \mathrm{mg}$ and amlodipine $5 \mathrm{mg}$ daily. Headache subsided with paracetamol. The patient was discharged home on oral steroids with follow-up appointments scheduled with rheumatology.

\section{DISCUSSION}

Systemic lupus erythematosus is the prototypic autoimmune disease characterized by heterogeneous, multisystem involvement and production of an array of autoantibodies leading to inflammatory tissue damage. The cSLE has an incidence ranging from 0.36 to 2.5 per 100,000 per year anda prevalence ranging from 1.89 to 25.7 per 100, 000 [4]. The disease also shows a significant ethnic variability with higher incidence in African, Hispanic and Asian populations [5, 6]. Albeit uncommon, onset of pediatric SLE is described even in children younger than 2 years of age. The female to male ratio with pediatric SLE changes from 4:3 with disease onset during the first decade of life to $4: 1$ during the second decade to 9:1 in aSLE, and decreases to 5:1 in SLE commencing after the age of 50 year [14]. The data (summarized in Table-1) showed that common initial presentations of cSLE included constitutional symptoms, renal disease, musculoskeletal and cutaneous involvement. Less frequently involved at cSLE presentation were the neuropsychiatric, pulmonary and cardiac systems, with pericarditis reported in $3-24 \%$ of cases at presentation [15].

Table-1: Frequency of selected presenting clinical features of childhood-onset SLE

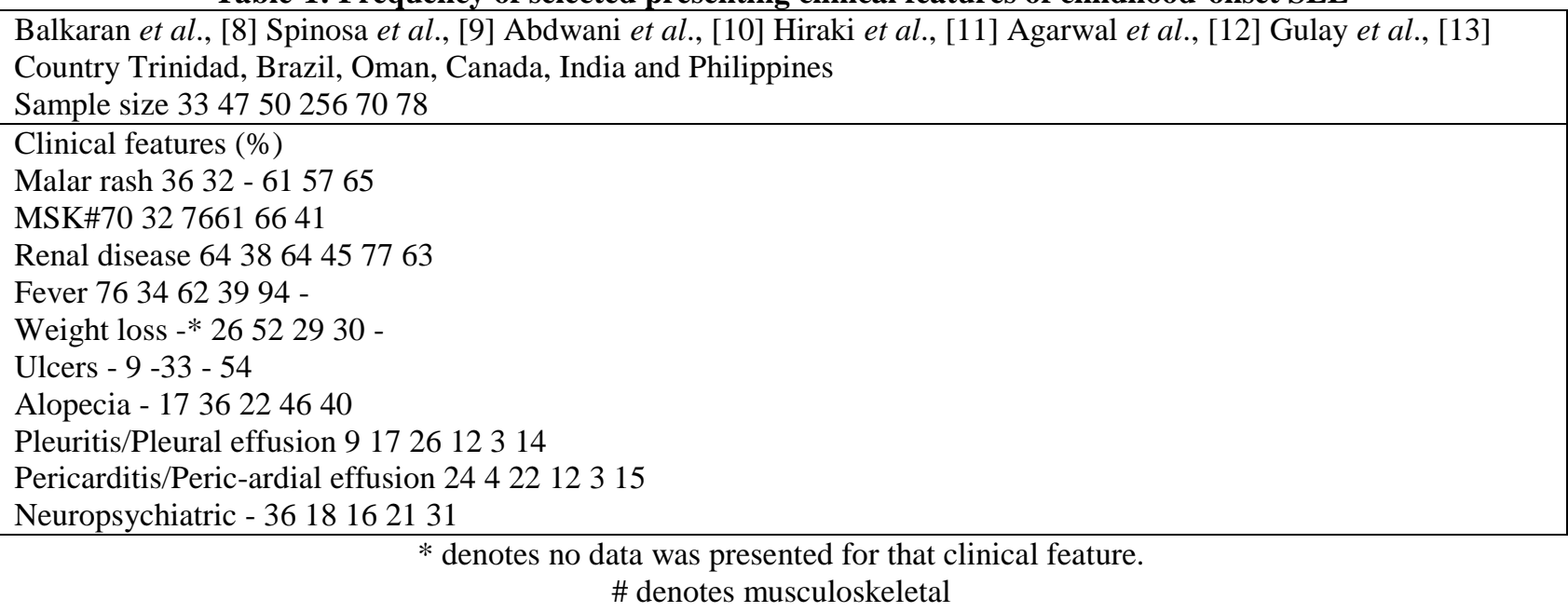

Rashes occur frequently in cSLE, but only 30$50 \%$ manifest typical butterfly rash. Cutaneous lesions may take the form of photosensitive rash, recurrent urticarial, bullae, vasculitic nodules, or chronic ulceration. Discoid lupus erythematosus is unusual in cSLE [16]. Arthritis affects over $80 \%$ of children with SLE at some point. Usually, the arthritis involves the small joints of hand and feet with pain and swelling. Although the arthritis in cSLEis nondeforming, and responds well to anti-inflammatory medication significant arthritis at presentation is found in $40 \%-60 \%$ of children and adolescents [16].

The most common hematologic manifestation of cSLE is anemia. Usually the anemia is not coomb's positive hemolytic anemia with reticulocytosis; rather, it is a microcytic anemia of chronic disease. Leukopenia and thrombocytopenia are also common but not invariably present [17].

Renal disease is evident in nearly two-thirds of patients with cSLE. Renal manifestations range from mild glomerulonephritis to sudden renal failure. Haematuria, proteinuria, and hypertension may be present in any combination. Renal biopsy should be performed if necessary to confirm the diagnosis, to investigate unexplained changes in renal function, and when the clinician is considering or monitoring the effects of aggressive therapy. Renal involvement is categorized according to criteria developed by World Health Organization. Mild clinical manifestation of renal involvement is usually well controlled with corticosteroid and diuretic agents. Persistent renal disease usually requires immunosuppressive therapy. 
Chronic glomerular scarring is prevented by cyclophosphamide over the intermediate term. The systemic use of intravenous cyclophosphamide has been successful in children with diffuse proliferative glomerulonephritis and useful in membranous glomerulonephritis. More recently, mycophenolate mofetil has shown early promise, but its efficacy in routine practice is limited by the poor compliance. Monitoring of the patients with lupus nephritis is very essential. Adult series suggest that maintaining a creatinine clearance of $70 \mathrm{~mL} / \mathrm{min}$ per 1.75 square meter is adequate [17].

Central nervous system involvement occurs in $20 \%-30 \%$ of children with SLE. Psychosis, personality change, seizure, chorea, transverse myelitis, peripheral neuropathy, and pseudotumor cerebri all may the presenting manifestations. Delirium, hallucinations, seizures, and coma are most common objective neurologic signs in cSLE. The reported frequency of neuropsychiatric manifestations is lower in that in adults. Most often, central nervous system involvement occurs early in the natural course of cSLE. Frequently, it first become evident during or worsens immediately after the initiation of corticosteroid therapy. The explanation for this is uncertain, but these symptoms frequently resolve with pulse methylprednisolone therapy [17].

\section{Conclusion}

SLE is a multi-system autoimmune disorder. Besides significantly more active disease at the time of disease onset, there is also more active disease over time with pediatric SLE when compared to aSLE. Some children and adolescents with SLE are acutely ill at presentation. Multiple faces of aggressive lupus including fever, rash, joint pain, pancytopenia, haematuria, proteinuria, seizures, psychosis, sepsis etc may be present simultaneously or in a rapid sequence making a special challenge for the physicians to encounter the illness. High index of suspicion is necessary to diagnose the disease to initiate appropriate therapy.

\section{REFERENCES}

1. Silverman E, Eddy A. Systemic Lupus Erythematosus. In: Cassidy JT, Petty RE, Laxer RM, Lindsley CB, editors. Text book of Pediatric Rheumatology 6th edition. Philadelphia: Elsevier Saunders; 2011; 315-343.

2. Ardroin SP, Schanberg LE. Systemic Lupus Erythematosus. In: Kliegman RM, Stanton BF, Geme III JW St, Schor NF, Behrman RE, editors. Nelson Textbook of peidatrics.19th edition. Philadelphia: Elsevier Saunders; 2012; 841-846.

3. Benseler SM. Silverman ED. Systemic Lupus Erythematosus. Pediatr Clin N Am. 2005; 52 (2): 443-67.
4. Pineles D, Valente A, Warren B, Peterson MGE, Lehman TJA, Moorthy LN. Worldwide incidence and prevalence of pediatric onset systemic lupus erythematomsus. Lupus. 2011; 20: 1187-92.

5. Hiraki LT, Susanne M.B, Tyrrell PN, Harvey E, Hebert D, Silverman ED. Ethnic Differences in Pediatric Systemic Lupus Erythematosus. J Rheum. 2009; 36: 2539-46.

6. Lau CS, Yin G, Mok MY. Ethnic and geographical differences in systemic lupus erythematosus: an overview. Lupus 2006; 15: 715-19.

7. Mina R, Brunner HI. Pediatric lupus-Are there differences in presentation, genetics, responseto therapy, damage accrual compared to adult lupus? Rheum Dis Clin N Am. 2010; 36 (1): 53-80.

8. Balkaran BN, Roberts LA, Ramcharan J. Systemic lupus erythematosus in Trinidadian children. Ann Trop Paediatr. 2004;24:241-4.

9. Spinosa MJ, Bandeira M, Liberalesso PB, Vieira SC, Janz Jr LL, Sá EG, Löhr Jr A. Clinical, laboratory and neuroimage findings in juvenile systemic lupus erythematosus presenting involvement of the nervous system. Arquivos de neuro-psiquiatria. 2007 Jun;65(2B):433-9.

10. Abdwani R, Al-Abrawi S, Sharef SW, Al-Zakwani I. Geographical Clustering of Juvenile Onset Systemic Lupus Erythematosus within the Sultanate of Oman. Oman Med J. 2013; 28(3):199203.

11. Hiraki LT, Benseler SM, Tyrrell PN, Hebert D, Harvey E, Silverman ED. Clinical and laboratory characteristics and long-term outcome of pediatric systemic lupus erythematosus: a longitudinal study. J Pediatr. 2008; 152(4):550-6.

12. Agarwal I, Kumar TS, Ranjini K, Kirubakaran C, Danda D. Clinical features and outcome of systemic lupus erythematosus. Indian Pediatrics. 2009 Aug 1;46(8):711-5.

13. Gulay CB, Dans LF. Clinical presentations and outcomes of Filipino juvenile systemic lupus erythematosus. Pediatric Rheumatology. 2011 Dec 1;9(1):7.

14. Mina R, Brunner HI. Pediatric lupus-are there differences in presentation, genetics, response to therapy, and damage accrual compared with adult lupus?. Rheumatic Disease Clinics. 2010 Feb 1;36(1):53-80.

15. Maharaj SS, Chang SM. Cardiac tamponade as the initial presentation of systemic lupus erythematosus: a case report and review of the literature. Pediatric Rheumatology. 2015 Dec $1 ; 13(1): 9$.

16. King KK, Kornreich HK, Bernstein BH, Singsen $\mathrm{BH}$, Hanson V. The clinical spectrum of systemic lupus erythematosus in childhood. Arthritis and rheumatism. 1977 Mar 1;20(2 Suppl):287-94.

17. Daniel JW, Bevra HH. DUBOIS' Lupus Erythematosus and Related Syndromes. $8^{\text {th }}$ edition, 495-505. 